vaccination rate of more than $90 \%$ without such laws, and the present social climate in Britain makes it extremely unlikely that such laws would be accepted here. Nevertheless, vigorous encouragement at school entry ${ }^{19}$ is a policy worth considering.

NORMAN D NOAH

Consultant Epidemiologist,

PHLS Communicable Disease Surveillance Centre,

London NW9 5EQ

1 Center for Disease Control. Goal to eliminate measles from the United States. Morbidity Mortality Weekly Report 1978;27:391.

Centers for Disease Control. Measles-United States. Weeks 45-48 1981. Morbidity Mortality Weekly Report 1982;30:621-2.

${ }^{3}$ National Advisory Committee on Immunization. Measles surveillance. Statement on elimination of indigenous measles in Canada. WHO Weekly Epidemiological Record 1980;55:305-7.

4 Albritton RB. Cost-benefits of measles eradication. Effects of a federa intervention. Policy Analysis 1978;4:1-21.

5 Witte JJ, Axnick NW. The benefits from 10 years of measles immunization in the United States. Public Health Rep $1975 ; 90: 205-7$

- Creese AL, Henderson RH. Cost-benefit analysis and immunization programmes in developing countries. Bull WHO 1980;58:491-7.

7 Yorke JA, Nathanson N, Pianigiani G, Martin J. Seasonality and the requirements for perpetuation and eradication of viruses in populations. Am $\mathcal{f}$ Epidemiol 1979;109:103-23.

${ }^{8}$ Rutstein DD. Controlling the communicable and the man-made diseases. $N$ Engl f Med 1981 ;304:1422-4.

- Frank JAJP, Hoffman RE, Mann JM, Crowe JD, Hinman AR. Imported measles. A potential control problem. $\mathcal{F} A M A$ 1981;245:264-6.

10 Smith H. Measles again. $\mathrm{Br}$ Med $\mathcal{F}$ 1980;280:1616-7.

11 Department of Health and Social Security. Health and personal social services statistics for England. London: HMSO, 1978:184, tables 10-3.

12 Bussey AL, Holmes BS. Immunisation levels-need they decline? Lancet 1977 ;ii :970-1.

13 Bussey AL, Harris AS. Computers and the effectiveness of the measles vaccine campaign in England and Wales. Community Med 1979;1:29-35.

14 Wright HJ. Acceptance of measles vaccine. Lancet $1977 ;$ ii:554.

15 Wilkinson P, Tylden-Pattenson L, Gould J. Professional attitudes towards vaccination and immunisation within the Leeds Area Health Authority (Teaching). Public Health 1979;93:11-5.

16 Adjaye N. Measles immunization. Some factors affecting non-acceptance of vaccine. Public Health $1981 ; 95: 185-8$

17 Miller CL. Severity of notified measleś. Br Med f 1978;i:1253.

18 Smith H. Measles again. Br Med f 1980;280:766-7.

19 Miller C. Measles again. $\mathrm{Br}$ Med $\mathcal{f} 1980 ; 280: 1451$.

${ }^{20}$ Robbins KB, Brandling-Bennet D, Hinman AR. Low measles incidence association with enforcement of school immunization laws. Am F Public Health $1981 ; 71: 270-4$.

21 World Health Organisation. Incidence of 5 vaccine preventable diseases and immunisation coverage. WHO Weekly Epidemiological Record 1981; $56: 369-72$.

\section{What has happened to charity?}

Though many charitable people within and outside the profession continue to help, public distrust and medical indifference are causing a crisis in organ transplantation. Last year saw 596 renal transplant operations-a $24 \%$ fall compared with the 784 in 1980 . Yet results are improving and this potentially lifesaving treatment for young people with disease of the kidneys and other vital organs could be made much more widely available. Dialysis units are overworked and most have difficulty in accepting new cases. The selection criteria for treatment have become more restricted, and some patients with renal failure cannot be admitted. The inadequate number of transplantations has overstrained the resources devoted to dialysis by a health service already suffering from impaired funding.

The new immunosuppressive drug cyclosporin $\mathrm{A}$ has improved the one-year functional survival of kidney grafts from unrelated cadaver donors from a previous $50-55 \%$ to over $80 \%$ and has permitted transplantation of the heart and both lungs for the first time. ${ }^{12}$ Kidney grafts can lead to full rehabilitation and restore activity without the restrictions of regular dialysis, but none of the 30 transplant centres in Britain is fully occupied. Most units are performing fewer than half the operations for which they were designed. The alternative of kidney transplants from live related donors has never been popular in Britain; it accounts for about $10 \%$ of the grafts performed, despite the fact that for a well-matched sibling donor graft the five-year functional survival is around $80 \%$.

In Britain at the end of 1981 the waiting list for renal transplants was 2273 , an increase of $30 \%$ compared with two years ago, and 1500 new cases are added each year. The current annual number of operations needs to be doubled to treat the new patients and begin to reduce the backlog. There could be more than enough cadaver donors to supply all the transplantation needs. In theory, 8000 kidneys could come from the 4000 patients with brain death each year. In practice, some of these patients would not be suitable donors owing to the circumstances of death and the associated injuries. ${ }^{3} 4$

The causes of the shortfall are not difficult to find. The fragile flower of public support and confidence was flourishing, nurtured by the medical profession's acceptance of a role in co-operating in organ donation, and refusal to give consent by relatives of the deceased was rare; then the growing plant was viciously uprooted by the $\mathrm{BBC}$. Its first programme on brain death, on Panorama, was like a trial in a totalitarian countrya prosecution with no defence and with irrelevant witnessesand it undermined the British criteria of brain death. The television debate that followed some months later was disrupted at the last moment by one of the opponents of the British criteria, who claimed to know of two patients satisfying those criteria who had subsequently recovered fully. These two powerful exploitations of public fears undermined the integrity of the profession and the reliability of its methods of diagnosis. The harm could scarcely be expected to be undone by a letter in the Lancet ${ }^{5}$ by the doctor concerned stating that he was withdrawing unreservedly the statement made on television. The British criteria of brain death have been fully vindicated, ${ }^{4}$ and the general care of patients with severe brain damage has improved throughout the country as a result of their acceptance. These criteria have nothing to do with transplantation but merely indicate when further attempts to resuscitate a dead person are futile, can only cause distress, and should be abandoned.

All hospitals in a region send patients with renal failure to the regional transplant centre, but some shirk the responsibility to help with organ donation. Some institutions where relatives previously almost always gave consent now have a high incidence of refusals. Some doctors seldom co-operate in organ grafting, and their prejudices have been reinforced with the excuse that the public does not want transplantation. This enables them to avoid an issue that would otherwise require extra work and harrowing emotional interviews.

What, then, can be done to improve this sad picture ? Firstly, the BBC, having caused a grave injury with the misuse of its immense power, has a moral obligation to put the record straight. That requires both scientific documentaries and portrayals of the plight of the many young patients who are at present being denied treatment. Each month patients are dying from renal disease because they have not been able to find spaces on dialysis programmes owing to the lack of throughput with transplant operations.

Secondly, doctors working in neurosurgical and intensive care units should accept as an ethical medical obligation the need to help with organ donation; and those removing kidneys 
for grafting should bear in mind the need for other organs such as livers, pancreases, and hearts. More than a third of the 15-20 livers transplanted yearly in Britain come from generous donations in Northern Europe, but the cost of transportation is considerable. In America and Holland doctors who take part in extra work concerned with the donation of organs are paid personally, or the fee is given to the institution. Such an idea might be re-examined in Britain. The amount spent on such extra-duty payments would be far less than the cost of keeping patients on dialysis.

Some countries have opted for new legislation on organ donation from dead donors, the diagnosis of death, and the removal of organs from live volunteers. In Britain the Human Tissue Act 1961 was drafted at a time when organ transplartation was not practised. The Act has not been tested in law, and certain ambiguities have caused disquiet in the profession. The present law is a combination of "opting in" and "opting out." If the deceased's wishes are known the next-of-kin is approached to determine what those wishes would have been (not to ask the relatives' consent). If the next-of-kin is not available removal of organs may be undertaken provided that there is no objection from the coroner, who can order removal of organs in any case under his authority without being challenged by the relatives or anyone else.

An interview with the relatives when no donor card has been found can be extremely distressing, particularly if the patient's death is sudden and unexpected. Often, and especially in the case of children, it is impossible to discuss the question of organ donation with relatives in time for the organs to be used. Yet frequently when the immediate shock has passed off the relatives come forward too late and ask whether the organs can be used for grafting, or later regret that they were not used. Many people would rather not discuss these matters but would prefer that the organs should simply be taken and used for transplantation. Such a procedure would be similar to a coroner's necropsy, in which the relatives are not asked to consider the details. In countries where there is a complete opting-out system, such as France, Austria, and Denmark, the relatives are not ignored. Despite the fact that the law does not require it, if the relatives are available and can be approached without adding to their distress the doctors will still discuss the matter of organ donation and will not violate the wishes of the next-of-kin. Various opting-out schemes have been suggested by which objectors to organ grafting could register their names and those of their dependants on a central computer that would always be contacted before organs were removed from a dead person. If the deceased's name or that of his family was not recorded through the computer doctors could assume that there was no objection to organ removal.

Even if most of the population favoured an opting-out system or an assumed consent powerful voices would no doubt be raised by a minority claiming yet another incursion on personal liberties. A government already troubled by other matters might be reluctant to introduce new legislation, but without government support a change in the law is unlikely. And even if the law were to be changed there would be little improvement in organ donation unless the good will and confidence of the public and profession were restored. The facts should speak for themselves. Organ transplantation is an essential part of the treatment of renal failure and other life-threatening disorders and the supply of donor organs must be improved. Britain has a proud record of generous help for those suffering and in need and this charitable tradition should be preserved.

Professor of Surgery, University of Cambridge,

R Y CALNE

Addenbrooke's Hospital, Cambridge CB2 2QQ
${ }^{1}$ Calne RY, White DJG, Evans DB, et al. Cyclosporin A in cadaveric organ transplantation. Br Med F 1981;282:934-6.

2 Reitz BA, Wallwork JL, Hunt SA, et al. Cyclosporin A for combined heart-lung transplantation. In: White D, ed. Proceedings of an international symposium on cyclosporin $A$. Amsterdam: Elsevier (in press).

${ }^{3}$ Anonymous. Kidney transplantation in the United Kingdom. Lancet 1982 ; $\mathrm{i}: 88$.

${ }^{4}$ Jennett $\mathrm{B}$, Gleave J, Wilson P. Brain death in three neurosurgical units. Br Med f 1981 ;282:533-9.

${ }^{5}$ Paul R. Survival after brain death: withdrawal of allegation. Lancet 1981 ; i:677.

\section{Pregnancy and immunological disorders}

The mechanisms by which the fetal homograft escapes immunological rejection continue to fascinate immunologists and have still not been fully worked out. ${ }^{12}$ The maternal circulation is in direct contact with the syncytiotrophoblast lining the chorionic villi of the placenta, and it is the permeability of the syncytiotrophoblast to cells and soluble factors that determines the extent to which the maternal immune system becomes sensitised to fetal antigens and fetal immune reactions affect immunological events in the mother. Even if such traffic does not usually lead to rejection of the fetus, it may nevertheless influence maternal immune reactions.

Does pregnancy induce some measure of maternal immunosuppression? Some laboratory work has suggested some depression in the responses of maternal lymphocytes to mitogens. This suppression has been attributed to immunosuppressive factors in the serum during pregnancy, such as alpha-2-glycoproteins ${ }^{3}$ and hormones, rather than to intrinsic defects in lymphocytes. These observations are, however, controversial-not least because of simple technical points such as the variation that depends on whether the assays are performed in plasma or serum. ${ }^{4}$ Furthermore, the lymphocyte responses are not generally accepted as being suppressed in pregnancy or physiological concentrations of hormones such as progesterone, oestrogens, and corticosteroids as being immunosuppressive. ${ }^{5}$ Specific immune responses are not the only host defence factors to have received attention in this context; for example, granulocyte chemotaxis is also reported to be depressed by serum from pregnant women. ${ }^{6}$

One means of judging the extent of maternal immunosuppression is to examine the course of infectious diseases in pregnancy. Most virus infections do not produce unusually severe disease in pregnancy and are not accompanied by loss of the fetus, ${ }^{7}$ but immune responses to some viruses, and in particular to cytomegalovirus and rubella virus, are impaired. This deficiency is not, however, absolute. Thus in one study no evidence of rubella virus infection was found in the fetuses of mothers immunised with attenuated live rubella virus. ${ }^{8}$ Nevertheless, the risks of an unusually severe infection cannot be discounted in pregnancy; for example, meningitis and septicaemia after infection with Haemophilus influenzae type $\mathrm{B}$ have been reported in pregnancy, complications usually observed only in children. ${ }^{9}$ In addition, clinically silent viral infections may be detected only serologically but may have pathological consequences for both the mother and the fetus. For example, there is some suggestion that fetal abnormalities may be more frequent in mothers who have acquired EpsteinBarr virus infections during pregnancy, ${ }^{10}$ and in another study a high or rising serum antibody titre to $\mathrm{BK}$ polyomavirus was detected in 45 of 430 pregnant women. ${ }^{11}$

Given these uncertainties, the clinical effects of pregnancy 